\title{
O documentário como gênero audiovisual
}

\author{
Cristina Teixeira Vieira de Melo*
}

\section{Resumo}

Neste artigo, objetivamos apontar quais os elementos constitutivos do documentário são capazes de diferenciá-lo de outros gêneros audiovisuais, como o filme de ficção e a reportagem jornalística na TV. Sustentamos que a marca característica do documentário é seu caráter autoral, definido como uma construção singular da realidade, um ponto de vista particular do documentarista em relação ao que é retratado. Alguns elementos lingüístico-discursivos evidenciam esse caráter autoral: a maneira como se dá voz aos outros, a presença de paráfrases discursivas e um efeito de sentido monofônico. Ainda destacamos a criatividade usada no processo de edição e montagem como um importante índice de autoria. Tomamos como aparato teórico de análise estudos no campo do Cinema e conceitos do âmbito da Linguística Textual e da Análise do Discurso.

Palavras-chave: documentários, autoria, análise do discurso.

\section{O diálogo entre o documentário e outros gêneros audiovisuais}

A comunicação pressupõe a existência de gêneros. Mikhail Bakhtin (1992) já dizia que cada esfera de utilização da língua elabora tipos relativamente estáveis de enunciados, sendo isso o que ele denominou de gêneros do discurso. Segundo Bakhtin, o indivíduo pode ignorar totalmente a existência teórica dos gêneros do discurso, mas, na prática, usa-os com segurança e destreza.

Muitas vezes, os gêneros discursivos têm marcas lingüísticas mais ou menos estereotipadas e identificáveis. É o caso de expressões como: "era uma vez ..." (na abertura de narrativas infantis), "prezado amigo" (na abertura de cartas), "conhece aquela do português..." (em piadas) etc.

* Cristina Teixeira Vieira de Melo - Professora Visitante/ UFPE

Comun. Inf., v. 5, n. 1/2, p.25-40, jan./dez. 2002 
O gênero documentário não pode ser definido a partir da presença de determinados enunciados estereotipados ou de tipos textuais fixos (narração, descrição, injunção, dissertação). No entanto, não temos dúvidas de que o documentário é um gênero com características particulares, e que são essas características que nos fazem apreendê-lo comotal.

Independentemente do tema tratado (violência, ecologia, história, arte, cultura, biografia etc), somos capazes de identificar e diferenciar um documentário de outros tipos de produção audiovisual (filmes de ficção e reportagens de TV, por exemplo). É bem verdade que no momento da fruição, o espectador pode cometer equívocos de interpretação. A inexistência de gêneros puros é um dos fatores que podem levar a equívocos. Neste ponto, cabe destacar a seguinte passagem de Rondelli (1998:29):

\begin{abstract}
"No caso da televisão, os telejornais e documentários deveriam ser o reino dos discursos sobre o real, enquanto as telenovelas e seriados, o lugar da ficção. Entretanto, esses gêneros além de não serem puros no modo como narrativamente constroem suas representações, convivem com uma série de outros gêneros que transitam entre dois pólos sem nenhum compromisso de serem fiéis ou coerentes com a realidade ou com a ficção, e que ficam mergulhados numa região cinzenta".
\end{abstract}

Recentemente, por exemplo, milhões de espectadores ao redor do mundo equivocaram-se com relação a A Bruxa de Blair (Myrica $\&$ Sanchez, 1999). O filme, de natureza ficcional, foi anunciado como sendo uma 'ficção documentada'. Para muitos, ele realmente funcionou como um documentário, principalmente em decorrência do estilo das imagens captadas (câmera na mão).

De maneira oposta a A Bruxa de Blair, há casos em que o cineasta realiza um documentário com formato ficcional. É só lembrar do aplaudido Ilha das Flores (Jorge Furtado, 1989) ou do polêmico Nós que aqui estamos por vós esperamos (Marcelo Masagão, 1999).

"Esse não é um filme de ficção" - é assim que se inicia Ilha das Flores. Esse ato de enunciação é bastante curioso porque, ao afirmar o que o filme não é, o diretor termina definindo o que ele é. Trata-se de uma autocategorização. Diante de tal anúncio, criam-se expectativas com relação ao gênero que está sendo produzido. Se não é ficção, o

Comun. Inf., v. 5, n. 1/2, p.25-40, jan./dez. 2002 
espectador supõe que seja ser um filme documental. No entanto, o que vem logo a seguir é uma narrativa ficcional, com personagens, direção de atores e criação de cenários.

O documentário Nós que aqui estamos por vós esperamos é construído a partir de um mosaico de imagens, umas que já fazem parte da memória coletiva, e outras, até então, desconhecidas. Na maior parte das vezes, as imagens desconhecidas retratam pessoas anônimas em atividades de trabalho ou lazer. São, portanto, documentos históricos. No filme de Masagão, entretanto, essas imagens adquirem nova dimensão. As pessoas ganham uma identidade ficcional, ou seja, embora as imagens sejam reais, as histórias contadas são ficcionais. Masagão foi criando personagens que nunca existiram, mas que poderiam ter sido reais em seus respectivos tempo e espaço.

É oportuno lembrar ainda o caso em que o documentário adquire ares de propaganda. Encaixam-se aqui documentários de caráter institucional e filmes como Triunfo da Vontade (1935) e Olympia (1938), ambos dirigidos por Leni Reifenstahl. Por vezes, o espaço entre o documentário e a propaganda é tão tênue que os documentaristas pós-griersonianos ${ }^{1}$, para evitar apelidos como o de propagandista, muitas vezes negaram-se a si mesmos o papel de "interpretadores".

Os exemplos listados acima mostram que a região de fronteira entre o documentário e outras produções audiovisuais é, muitas vezes, nebulosa.

\section{Cinema e documentarismo}

O documentário ocupa uma posição ambígua e polêmica na história, teoria e crítica do cinema. Se, por um lado, recorre a procedimentos próprios desse meio - escolha de planos, preocupações estéticas de enquadramento, iluminação, montagem, separação das fases de préprodução, produção, pós-produção, etc -, por outro, procura manter uma relação de grande proximidade com a realidade, respeitando um determinado conjunto de convenções: registro in loco, não direção de atores, uso de cenários naturais, imagens de arquivo etc. Vale salientar que embora o segundo conjunto de convenções acima referido represente recursos característicos do documentário, garantindo autenticidade ao que é representado, não lhe é exclusivo ou imprescindível. $\mathrm{Ou}$ seja, um filme ficcional também pode se valer de tais estratégias, bem

Comun. Inf., v. 5, n. 1/2, p.25-40, jan./dez. 2002 
como a presença ou ausência de apenas um desses elementos não é a garantia de que se tem pela frente um documentário.

Por exemplo, a simples seqüencialização de documentos, por si só, não caracteriza um documentário. São inúmeras as produções ficcionais que utilizam imagens ou sons documentais no sentido de dar maior força à narrativa. A presença de registros históricos em filmes como Forrest Gump (1994, Robert Zemeckis), Zelig (1983, Woody Allen) e JFK (1991, Oliver Stone) não os tornam documentários. Assim, a inserção de imagens reais em filmes não é condição única para assegurar o status de documentário a uma produção. A recíproca também é verdadeira: a utilização de recursos próprios da ficção não invalida o caráter documental de um filme.

Uma diferença marcante entre o documentário e o cinema de ficção é aquele não poder ser escrito ou planificado de modo equivalente a este último; o percurso para a produção do documentário supõe uma liberdade que dificilmente se encontra em qualquer outro gênero. Um documentário é construído ao longo do processo de sua produção. Mesmo existindo um roteiro, o formato final somente se define com as filmagens, a edição e a montagem.

Outra diferença recai sobre o papel do sujeito filmado. De acordo com Penafria (1999), no documentário, a perfectibilidade do filme dialoga com a imperfectibilidade dos "intérpretes", personagens reais do mundo existente. Como os diálogos não podem ser previamente escritos e costumam não ser previsíveis, diz-se que um documentário é o "argumento encontrado" (Penafria, 1999:109).

De tudo o que foi exposto até agora, verificamos que no documentário existe uma possibilidade enorme de variação quanto à utilização de determinados recursos. O documentarista pode (ou não):

- usar a figura do locutor (on ou off);

- construir o filme apenas em cima de depoimentos;

- utilizar o recurso da reconstituição para contar a história;

- criar personagens para dar maior dramaticidade à narrativa;

- apresentar documentos históricos, etc.

Essa lista pode ainda ser ampliada. O que parece permanecer sempre como característica fundamental do documentário é o fato de ser um discurso pessoal de um evento que prioriza exigências mínimas de verossimilhança, literalidade e o registro in loco.

Quanto ao registro in loco, ressalta-se que o documentário deve, o máximo possível, apresentar todas as evidências factuais em seu

Comun. Inf., v. 5, n. 1/2, p.25-40, jan./dez. 2002 
contexto original. No entanto, se por qualquer motivo o documentarista não consegue filmar um acontecimento no momento em que ocorre ou habitualmente ocorre, ele pode usar imagens de arquivo (documento histórico), fazer uso da reconstituição (recurso legitimado pela escola de Grierson), voltar ao local dos acontecimentos ocorridos no passado ou utilizar depoimentos das pessoas envolvidas, numa tentativa de se aproximar do ocorrido. Ou seja, não é obrigatório o documentarista colocar-se no terreno do acontecimento "aqui e agora".

Diante de tal leque de possibilidades, resta perguntar qual o sentido que estamos dando à expressão in loco. Originalmente, o termo significa o lugar (espaço) onde é colhida a informação, mas que, segundo a semiologia da imagem, assimilou o sentido de localização espaço-temporal. Levando isso em consideração, subdividimos o conceito de in loco. A classificação que ora apresentamos ainda precisa ser amadurecida, mas é uma tentativa de sistematização. Vejamos:

a) in loco contemporâneo - o tempo e o espaço do fato/objeto retratado são contemporâneos ao da produção do documentário. Prevalece a idéia do "aqui e agora";

b) in loco (re)construído - faz referência ao passado, mas acontece no tempo presente. Há uma tentativa de melhor contextualizar o fato (passado) a partir de algum tipo de interferência do documentarista no espaço (presente). Temos o registro in loco (re)construído quando, por exemplo, se constroem cenários/maquetes para que o espectador possa visualizar melhor o objeto ou a ação;

c) in loco referencial evolutivo - também faz referência ao tempo passado, mas, neste caso, não há uma interferência direta do documentarista no ambiente. A transformação do in loco decorre da ação natural do tempo e da História sobre o espaço geográfico, sobre a paisagem. É o caso das entrevistas realizadas em locais onde aconteceu determinado fato. Nesse caso, as entrevistas podem ser consideradas um registro in loco.

Fica claro que o in loco contemporâneo é construído a partir do presente, enquanto as duas outras categorias mantêm alguma relação com o passado, constituindo-se como uma espécie de retomada, de resgate. Vale ressaltar ainda que qualquer tentativa de reconstituição dos acontecimentos vai exigir um trabalho de reconstrução.

$\mathrm{O}$ fato de ser um discurso sobre o real e utilizar imagens in loco são características que aproximam o documentário do discurso jornalístico. A nosso ver, contudo, ele não é um gênero propriamente

Comun. Inf., v. 5, n. 1/2, p.25-40, jan./dez. 2002 
jornalístico. Enquanto o jornalismo busca um efeito de objetividade ao transmitir as informações, no documentário predomina um efeito de subjetividade, evidenciado por uma maneira particular do autor/diretor contar a sua história. Por isso dizemos que o documentário é um gênero essencialmente autoral (aspecto que será explorado mais adiante).

Diante das dificuldades de apontar quais são os elementos de linguagem intrinsecamente constitutivos do documentário, nossa proposta é a de que, no processo de análise e de classificação, as características que aqui estão sendo chamadas de flutuantes (presença do locutor, de depoimentos, de registros históricos, reconstituições etc) sejam levadas em consideração e medidas em termos de gradação (mais forte, menos forte) dentro de um quadro comparativo com outros gêneros audiovisuais, especialmente com aqueles que fazem fronteira com o documentário (filme de ficção e reportagens de televisão).

\section{0 discurso sobre o real, ponto de aproximação entre jornalismo e documentarismo}

Como em outros discursos sobre o real, o documentário pretende descrever e interpretar o mundo da experiência coletiva. Essa é a principal característica que aproxima o documentário da prática jornalística. As informações obtidas por meio do documentário ou da reportagem são tomadas como "lugar de revelação" e de acesso à verdade ${ }^{2}$ sobre determinado fato, lugar ou pessoa. Diferentemente, portanto, do filme de ficção, no qual aceitamos o jogo de faz-de-conta proposto pelo diretor, não tendo, assim, cabimento discutir questões de legitimidade ou autenticidade; ao nos depararmos com um documentário ou matéria jornalística, esperamos encontrar as explicações lógicas para determinado acontecimento.

No entanto, não devemos esquecer que qualquer relato (independentemente de sua natureza) é sempre resultado de um trabalho de síntese, que envolve a seleção e a ordenação de informações.

Assim, tanto nas narrativas pessoais como nas jornalísticas, o sujeito-autor cria uma situação nova a partir de um fato que já passou. Essa situação nova não é um espelho fiel da realidade, mas sua representação. Dessa forma, mesmo configurando-se como um discurso sobre o real, documentários e reportagens não são reflexos, mas cons-

Comun. Inf., v. 5, n. 1/2, p.25-40, jan./dez. 2002 
truções da realidade social. Ou seja, no documentário ou na reportagem não estamos diante de uma mera documentação, mas de um processo ativo de fabricação de valores, significados e conceitos.

\section{$4 \mathrm{O}$ eterno mito da objetividade jornalística}

Apesar das constatações acima, o jornalismo toma a imparcialidade como um dogma. A "doutrina da imparcialidade jornalística" foi adotada pelos americanos, no início do século XX, para reagir à invasão do sensacionalismo na imprensa e se tornou norma em diversos manuais de redação e estilo não apenas nos Estados Unidos, mas também no Brasil. Depois de instalada, essa doutrina transformou-se em mito e vem permitindo aos veículos de comunicação camuflar a tendenciosidade das notícias veiculadas.

De acordo com Melo (1985), "a objetividade se converteu em sinônimo de verdade absoluta e é vendida como ingrediente para camuflar a tendenciosidade que existe na prática cotidiana dos veículos de comunicação". Ou seja, a aparente neutralidade dos veículos possibilita "vender" uma imagem de imparcialidade e, em consequiência, conquistar a credibilidade da opinião pública.

A imparcialidade jornalística vem sendo desmitificada por alguns estudiosos, mas, mesmo com esses avanços, boa parte dos jornalistas, professores e manuais de jornalismo insistem em apregoar a neutralidade da imprensa. É sensato admitir que para bem informar a opinião pública o melhor seria reproduzir os fatos com fidedignidade, precisão e exatidão, mas a imparcialidade é praticamente impossível de ser alcançada.

\section{A subjetividade é bem-vinda no documentarismo}

Ao contrário do que ocorre com os gêneros jornalísticos, nos quais se busca uma suposta neutralidade ou imparcialidade, no documentário a parcialidade é bem-vinda. O documentário é um gênero fortemente marcado pelo "olhar" do diretor sobre seu objeto. O documentarista não precisa camuflar a sua própria subjetividade ao narrar um fato. Ele pode opinar, tomar partido, se expor, deixando claro para o espectador qual o ponto de vista que defende. Esse privilégio não é concedido ao repórter, sob pena de ser considerado parcial, tendencioso e, em última instância, de manipular a notícia.

Comun. Inf., v. 5, n. 1/2, p.25-40, jan./dez. 2002 
Com relação a esse ponto, é oportuno resgatar os depoimentos de Amir Lbaki, diretor do festival de documentários É Tudo Verdade, e de João Moreira Salles, documentarista e um dos diretores, entre outros, de Notícias de uma Guerra Particular e Futebol, para a Folha de S. Paulo:

"A objetividade é uma utopia a perseguir para o jornalismo, seja escrito ou audiovisual, mas não para o documentário. O cinema não-ficcional é uma obra de arte que carrega a visão de mundo de seu criador, tanto quanto qualquer filme de ficção esteticamente engajado. Exige-se a busca de objetividade de uma reportagem da CNN ou de um especial da BBC, mas não de um documentário de Johan van der Keuken, de Frederick Wiseman ou de Geraldo Sarno. O compromisso aqui é com algo mais difuso e complexo do que a mera 'objetividade'. O documentarista procura ser fiel a um só tempo à sua verdade e à verdade dos personagens e situações filmadas. E, como dizia Oscar Wilde, a verdade pura e simples raramente é pura e jamais simples. Não se busca um recorte pretensamente objetivo ou neutro do mundo. O documentário oferta-nos, isso sim, um mundo novo, forjado no embate entre a realidade filmada e a sensibilidade de um cineasta. A vanguarda do documentário contemporâneo trabalha explicitamente esse enfrentamento" (Amir Labaki).

"Um documentário ou é autoral ou não é nada. Ninguém pode confundir um filme de Flaherty com um filme de Joris Ivens. Isso acontece porque Flaherty vê a realidade de forma inteiramente diferente de Ivens. A autoria é uma construção singular da realidade. Logo, é uma visão que me interessa porque nunca será a minha. É exatamente isso que espero de qualquer bom documentário: não apenas fatos, mas o acesso a outra maneira de ver" (João Moreira Salles).

Acreditamos não ser difícil concordar com a afirmação de que o documentário é uma obra pessoal, sendo absolutamente necessário e esperado que o diretor exerça o seu ponto de vista sobre a história que narra. A subjetividade e a ideologia estão fortemente presentes na narrativa do documentário , oferecendo representações em forma de texto verbal, sons e imagens. É impossível ao documentarista apagarse.

Comun. Inf., v. 5, n. 1/2, p.25-40, jan./dez. 2002 


\section{6 ponto de vista é uma questão ideológica e estética}

Penafria (1999) afirma que a escolha de um ponto de vista é uma escolha estética e implica, necessariamente, determinadas escolhas cinematográficas em detrimento de outras: determinados tipos de plano, determinadas técnicas de montagem, etc. Cada seleção que o documentarista faz é a expressão de um ponto de vista, quer ele esteja consciente disso ou não. Assim, o documentarista cria uma interpretação que se manifesta pela maior ou menor criatividade que imprime à sucessão dos elementos que o filme integra.

Podemos dizer que o tratamento da imagem no documentário é bem diferente daquele utilizado no jornalismo de TV. Numa passagem do seu livro A televisão levada a sério, Arlindo Machado (2000), fala sobre a linguagem do telejornal. Dessa passagem, gostaríamos de destacar as observações feitas sobre a questão da imagem:

“... acima de tudo e fundamentalmente, o telejornal consiste de tomadas em primeiro plano enfocando pessoas que falam diretamente para a câmera (posição stand-up), sejam elas jornalistas ou protagonistas: apresentadores, âncoras, correspondentes, repórteres, entrevistados, etc. De fato, o quadro básico do telejornal consiste no seguinte: o repórter em primeiro plano, dirigindo-se à câmera, tendo ao fundo um cenário do próprio acontecimento a que ele se refere em sua fala, enquanto gráficos e textos inseridos na imagem datam, situam e contextualizam o evento; se tudo isso for ao vivo, mais adequado ainda. Uma outra maneira de resolver a fusão no mesmo quadro de todos os elementos do telejornal é mostrar, em primeiro plano, o âncora lendo a notícia, enquanto a imagem correspondente ao que ele anuricia aparece ao fundo, inserida por chroma key ou projetada em monitores presentes no cenário. A descrição é banal, já que banal é também o quadro elementar de todo e qualquer telejornal. O telejornal se constrói da mesma maneira, se endereça de forma semelhante ao telespectador, fala sempre no mesmo tom de voz e utiliza o mesmo repertório de imagens sob qualquer regime político, sob qualquer modelo de tutela institucional (privado ou público), sob qualquer patamar de progresso cultural ou econômico" (MACHADO, 2000: 103/4 grifos nossos).

Comun. Inf., v. 5, n. 1/2, p.25-40, jan./dez. 2002 
No geral, não é essa sensação de mesmice que se tem quando se assiste a documentários. Normalmente, as imagens são bem elaboradas, sofisticadas, como no cinema.

\section{A polifonia de vozes}

Observamos também que a idéia de polifonia de vozes é operacionalizada de maneira diferente no documentário e no telejornalismo. No telejornalismo trabalha-se no sentido de que as vozes apareçam de forma mais ou menos autônoma, prescindindo de qualquer síntese global (Machado, 2000). No mesmo sentido, Fiske (1987: 304) afirma que:

“O telejornal é uma montagem de vozes, muitas delas contraditórias, e sua estrutura narrativa não é suficientemente poderosa para ditar a qual voz nós devemos prestar mais atenção, ou qual delas deve ser usada como moldura para, através dela, entender o resto".

Já no documentário, podemos supor que a tal síntese se revela no caráter autoral do gênero, traduzido pela relação estabelecida entre o ponto de vista e a maneira como a tese defendida pelo documentarista se materializa no filme. No documentário, a costura de vozes caminha para que, ao final, o espectador chegue a um entendimento claro de qual é o posicionamento do documentarista sobre o tema retratado. Tudo é trabalhado para assinalar o ponto de vista do diretor.

O modelo polifônico de telejornalismo pode ser acusado, não sem razão, de tentar mascarar o fato de que toda produção de linguagem emana de alguém ou de um grupo, de uma empresa, portanto, nunca é o resultado de um consenso coletivo, mas de uma postura interpretativa (interessada) diante dos fatos noticiados.

Estamos chamando atenção para o fato de que também no telejornalismo pode haver um emolduramento da notícia em determinada direção, decorrente das inúmeras mediações e jogos de interesses que envolvem o fazer jornalístico. Nesse contexto, a fala do locutor, repórteres e entrevistados pode configurar justamente a "síntese" de um juízo de valor.

"A menos que nós próprios sejamos os protagonistas, os eventos surgem para nós, espectadores, mediados através de repórteres (literalmente: aqueles que reportam, aqueles que contam o que viram), 
porta-vozes, testemunhas oculares e toda uma multidão de sujeitos falantes considerados competentes para construir "versões" do que acontece. (...) No telejornal, só existem mediações; os próprios enunciados de repórteres e protagonistas aparecem como mediações inevitáveis e como condição sine qua non do relato telejornalístico" (MACHADO, 2000: 102).

\section{A estrutura da narrativa}

Outra diferença fundamental entre o documentário e o jornalismo de TV diz respeito à presença do narrador. Conforme constata Machado (2000: 105), no telejornal, a voz que relata o fato (locutor, repórter) permanece sempre atada a um corpo, corpo este submetido, como os demais ao seu redor, à lei do espaço físico onde ele está situado.

Já no documentário, a presença do narrador não é obrigatória. Os depoimentos podem ser alinhavados uns aos outros sem a necessidade de uma voz exterior, oficial, unificadora, que lhes dê coerência. Isso não quer dizer que um documentário sem locutor não seja um discurso coerente. Nesses casos, a coerência, o sentido, manifesta-se na seleção e encadeamento dos depoimentos que compõem a narrativa.

Em documentários compostos por seqüencializações de depoimentos é muito comum a existência de paráfrases sob a voz de sujeitos diversos. Temos um sujeito A que introduz uma informação e um sujeito B que, à sua maneira, irá repetir ou se contrapor à informação que já havia sido anunciada por A. Nesse contexto, observamos que os hetero e autoparafraseamentos tornam-se indispensáveis para dar coesividade ao texto, criando um elo entre depoimentos isolados que ao serem postos em sequiência dão unidade à narrativa. Assim, os elos estabelecidos entre as paráfrases discursivas atuam como elementos importantes da argumentação. A relação parafrástica estabelecida entre os diversos depoimentos funciona como um local privilegiado de observação do caráter autoral do documentário. Ou seja, nessa relação fica revelada a ideologia, o posicionamento, a tese, o ponto de vista do documentarista acerca de seu objeto.

\section{A questão da autoria}

Como muito bem expõe Possenti (2001a), a noção de autor está relacionada à de singularidade que, por sua vez, não escapa de uma

Comun. Inf., v. 5, n. 1/2, p.25-40, jan./dez. 2002 
aproximação com a questão do estilo. A noção de estilo mais corrente é a romântica, compreendida como a expressão de uma subjetividade (unitária, psicológica). De acordo com Possenti, categorias como desvio e escolha, alternativamente utilizadas na tradição da estilística tanto para descrever um fato de língua (ou de texto) quanto para descrever uma atividade psicológica, confirmam essa inscrição romântica.

A escolha tem sido entendida como uma opção entre alternativas dadas, feita com plena consciência, quer das alternativas em si, quer do efeito (de sentido) que cada uma delas produziria. Um autor onisciente escolheria a melhor das alternativas para cada situação enunciativa, supondo que do outro lado os leitores se dariam conta de suas manobras. A noção de desvio funda-se também, em boa medida, no fator consciência. $\mathrm{O}$ desvio seria efeito de uma decisão pensada do autor. Segundo essa concepção, poder-se-ia dizer que se tem estilo - apenas e de fato - quando há um desvio em relação a uma linguagem que seria não marcada.

Diferentemente da moda romântica, em que a escolha é entendida como efeito do cálculo de um indivíduo, ela pode ser entendida como efeito de uma multiplicidade de alternativas - decorrente de concepções de língua como objeto heterogêneo -, diante das quais escolher não é um ato de liberdade, mas o efeito de uma inscrição (seja genérica, social ou discursiva). Portanto, trata-se de efeito de exigências enunciativas e não de efeito de personalidade.

Diante dessa exposição, cabe-nos perguntar como, então, encontrar autoria num texto, como distinguir textos com ou sem autoria. Possenti (2001b) sustenta que alguém se torna autor quando assume (sabendo ou não) fundamentalmente duas atitudes: dar voz a outros enunciadores e, ao mesmo tempo, marcar sua posição em relação ao que eles dizem. No fundo, é uma questão de como dar voz aos outros.

No caso do documentário, sabemos que ele só pode ser construído a partir de outros lugares enunciativos, de outras vozes. Durante a produção do documentário, o documentarista recorre a diversas fontes para coletar as informações que lhe são necessárias. Essas fontes tanto podem ser consultas a arquivos (dos quais se extrairão informações para integrar o documentário) como simples conversas com pessoas envolvidas ou conhecedoras do assunto abordado.

Neste último caso, o documentarista busca ouvir a opinião de várias pessoas sobre determinado acontecimento ou personalidade, seja para confirmar uma tese (caso, por exemplo, dos documentários bio-

Comun. Inf., v. 5, n. 1/2, p.25-40, jan./dez. 2002 
gráficos), seja para confrontar opiniões (caso dos documentários sobre conflitos urbanos, sociais, raciais, religiosos, etc). As entrevistas realizadas, portanto, são fontes de informação para construção do texto. As conversas podem integrar ou não o documentário. Na maior parte das vezes, o documentarista utiliza trechos dessas entrevistas na edição final.

Há casos de documentários construídos apenas em cima de depoimentos e há outros em que aparece a figura do locutor (on ou off), que se encarrega de alinhavar toda a história, ocupando uma posição de destaque na narrativa. Apesar de o locutor exercer função destacada na condução da narrativa, a principal fonte de informações vem mesmo dos depoimentos, aos quais ele dá apoio. Nesse aspecto, é interessante notar que surge uma relação parafrástica entre os enunciados produzidos pelo locutor e os enunciados dos entrevistados. Como já dissemos, a paráfrase é um tipo de repetição e tem demasiada importância para ofluxo da narrativa.

Assim, no documentário, "a suposta existência de um exercício livre e polifônico das vozes discursivas pode ser contestado pelo argumento de que a simultaneidade de várias vozes, embora independentes, se desenvolve a partir de um mesmo referencial, todas partem de um mesmo conjunto de fatos, previamente eleitos, postos à discussão pública" (RONDELLI,1998: 32).

Isto é, apesar da presença da polifonia, do interdiscurso, da heterogeneidade enunciativa, um efeito de sentido monofônico perpassa todo o documentário. Esse efeito de sentido de monofonia está intrinsecamente relacionado ao caráter autoral do gênero. Se por um lado, o documentarista dá voz aos seus retratados, por outro, almeja convencer o público de que a história que está sendo narrada tem uma moral, à semelhança das narrativas literárias.

Na literatura, as falas dos personagens são construídas de modo que caminhem pelo enredo como se o único propósito fosse o entretenimento do leitor; percebe-se sutilmente que, na realidade, elas revelam a verdadeira intenção do autor: persuadir. Nesse sentido, as vozes têm importância fundamental na argumentação. Ou seja, por trás de uma "historinha" aparentemente despretensiosa defendem uma moral, o que, na perspectiva de Gancho (1997), poderia ser considerada como "a mensagem do texto".

Afirmamos que o efeito de sentido final do documentário é monofônico porque, apesar de apresentar um emaranhado de vozes,

Comun. Inf., v. 5, n. 1/2, p.25-40, jan./dez. 2002 
que muitas vezes se opõem e se contradizem, uma voz tende a predominar na linha do discurso: aquela que traz em si o ponto de vista do diretor. Um meio de perceber como isso se dá é analisar as paráfrases discursivas presentes na construção do filme.

\section{Considerações finais}

Após tudo o que foi colocado aqui, fica provado que não existem receitas para a produção documental. Quando tentamos definir as características constitutivas do gênero documentário, verificamos que em torno dele existem mais elementos flutuantes do que fixos. Vejamos, então:

Quanto às especificidades técnicas, o documentário pode ser apresentado sob formato televisivo, cinematográfico ou digital (como preconiza Penafria). Na escala temporal, sua duraçãoé bastante variável. Em média, um filme tem entre trinta minutos e uma hora e meia.

Embora a temática do filme documentário, especialmente a partir da década de 30 , esteja associada à obrigatoriedade de uma responsabilidade social $^{3}$, verifica-se, na prática, a possibilidade de uma grande diversidade de temas (vida animal, ecologia, ciência, violência, costumes de um povo, personagens da História, etc).

$\mathrm{O}$ registro in loco, apesar de fundamental, pode ser obtido de diferentes formas: mediante o registro dos fatos concomitante com a produção do documentário (in loco contemporâneo); ou por meio do resgate de elementos (do tempo ou espaço) relacionados a um acontecimento passado (in loco de (re)construção e in loco referencial evolutivo). Assim, não é necessário que o documentarista vivencie os acontecimentos retratados no "aqui e agora". Ele pode trabalhar com reconstruções, reconstituições ou banco de imagens.

Vale ressaltar ainda que o mero registro de imagens e sons do mundo não reflete, por si só, o valor do gênero documentário. Exige-se uma intervenção, um posicionamento autoral do documentarista no modo como as imagens e sons se sucedem. "O documentário nãoé um filme vazado de qualquer implicação. Ele sempre se posicionou como um gênero em que o essencial é estimular uma reflexão sobre o mundo" (Penafria, 1999:76). Para tal, exige-se que o tema abordado seja visto a partir de determinado ponto de vista, que irá se refletir na maneira que o documentarista apresenta os fatos. O efeito de sentido final, portanto, é resultado não simplesmente do que se diz, mas essencial-

Comun. Inf., v. 5, n. 1/2, p.25-40, jan./dez. 2002 
mente de como se apresenta o tema. É justamente nessa relação entre conteúdo e forma (quê e como) que reside o caráter autoral do documentário, marca que elegemos como característica fundamental do gênero.

Acreditamos que a nossa definição de caráter autoral está muito próxima da noção de criatividade de Penafria (1999). Segundo ela, no documentário é necessário que a sucessão e/ou sobreposição de imagens e sons apresente não só o ponto de vista adotado pelo documentarista, mas também seja capaz de tornar o documentário um gênero atrativo. A isso ela chama de criatividade.

"Nos dois momentos cruciais para a construção do documentário, a fase de produção propriamente dita (filmagens) e a de pós-produção (montagem), o documentarista organiza diversos elementos: entrevistas, som ambiente, legendas, música, imagens filmadas in loco (incluindo as imagens de arquivo) reconstruções, etc. A organização implica variadas escolhas: pessoas, ângulos, sons, palavras, justaposições de imagens etc. (...) Cada seleção que se faz é a expressão de um ponto de vista, quer esteja ou não consciente disso. Assim, a sucessão das imagens e sons, cujo resultado final é um documentário, tem como linha orientadora o ponto de vista adotado e encontra na criatividade do documentarista seu principal motor" (PENAFRIA, 1999).

Muito próximas à Penafria, sustentamos que a noção de caráter autoral se liga, essencialmente, ao modo como no filme estão organizados os elementos que o compõem (texto verbal, imagens e sons) e que se adequam à apresentação de um determinado ponto de vista .

Por fim, podemos resumir as características fixas e flutuantes do documentário no seguinte quadro:

\section{Características Fixas Características Flutuantes}

Discurso sobre o real

Registro in loco

Caráter autoral
Suporte (digital, cinema, televisão)

Temática (biografia, cultura, ecologia, etc)

Presença do locutor (on ou off)

Uso de depoimentos

Uso de reconstituições

Uso de personagens ficcionais

Uso de documentos históricos

Comun. Inf., v. 5, n. 1/2, p.25-40, jan./dez. 2002 
Como já explicitado, sugerimos ainda que o documentário seja estudado dentro de um quadro comparativo entre o filme de ficção e a reportagem televisiva.

\begin{abstract}
In this text the autor points ou that the one of the most important characteristic of the documentaries is the presence of the author as a constructor of reality, because he frequently presents his particular point of view of what is being represented.

Keywords: documentary, author, discourse analysis.

\section{Notas}

1. Grierson, documentarista pertencente à escola inglesa de documentários.

2. Sabemos não existir uma verdade absoluta. O conceito deve ser entendido como uma versão dos fatos.

3. Por esse motivo, o documentário foi (e muitas vezes ainda é considerado) um filme de tom sério e pesado, cujos temas se relacionam com injustiças sociais.
\end{abstract}

\title{
Referências
}

BAKHTIN, Mikhail. Estética da Criação Verbal. Tradução de Maria Ermantina Gomes Pereira. São Paulo: Martins Fontes, 1992.

FISKE, John. Televison Culture. Londres: Methuen, 1987.

GANCHO, Cândida. Como analisarnarrativas. São Paulo: Ática, 1997.

MACHADO, Arlindo. A televisão levada a sério. São Paulo: Editora SENAC, 2000.

MELO, J. M. de. "A questão da objetividade no jornalismo". Cadernos Intercom/ IMS, São Paulo, v.7, p. 7-20, 1985.

PENAFRIA, Manuela. O filme documentário: história, identidade, tecnologia. Lisboa: Editora Cosmos, 1999.

POSSENTI, Sírio. Indícios de autoria. 2001. Mimeografado. . Enunciação, autoria e estilo. 2001. Mimeografado.

Comun. Inf., v. 5, n. 1/2, p.25-40, jan./dez. 2002 